\title{
Restrictive Cardiomyopathy, CTCAE
}

National Cancer Institute

\section{Source}

National Cancer Institute. Restrictive Cardiomyopathy, CT CAE. NCI Thesaurus. Code C55069.

A disorder characterized by an inability of the ventricles to fill with blood because the myocardium (heart muscle) stiffens and loses its flexibility. 